\title{
COMPARACIÓN MOLECULAR DE LA IDENTIDAD GENÉTICA DE GENOTIPOS DE MAÍZ DE DIFERENTE EDAD ${ }^{1}$
}

\author{
Germán Fernando Gutiérrez-Hernández², Elpidio García-Ramírez³, José Luis Arellano-Vázquez, \\ Juan Virgen-Vargas ${ }^{4}$, Guadalupe Ramírez-Sotelo ${ }^{2}$
}

\begin{abstract}
RESUMEN
Comparación molecular de la identidad genética de genotipos de maíz de diferente edad. Con base en el año de producción de la semilla 1994, 1996 y 2000 se realizó la comparación molecular de cuatro líneas endogámicas de maíz, generadas por el Programa de maíz del INIFAP: L1, L2, L3 y L4. Para ello, se extrajo el ADN de los embriones de las semillas con el cual se efectuó la RAPD y se establecieron las relaciones filogenéticas entre los tratamientos mediante el programa LCDMV (calculation software of molecular distances between varieties). Se utilizaron los parámetros: distancia de Seuil $=0$, confiabilidad del $95 \%$, el estimador de distancias de Nei y Li y el método del agrupamiento promedio (UPGMA). En la comparación por edades los dendogramas agruparon genotipos iguales con sus respectivas edades, destacando la similitud alcanzada para la unión de las edades de L2 (90 \%) y de L4 (80 \%); mientras que para L1 el valor de similitud fue del $70 \%$. La capacidad genotípica de las líneas bajo estudio para preservar su genoma fue mayor en L2, siguiéndole L4 y después L1. Los resultados indicaron la efectividad de la RAPD para diferenciar edades y genotipos genéticamente relacionados, así como para distinguir entre y dentro de las líneas de maíz independientemente de su edad.
\end{abstract}

Palabras clave: Zea mays, identidad genética, huella genómica, RAPDs, envejecimiento natural.

\begin{abstract}
Molecular comparison of the genetic identity of maize genotypes with different age. Based on year of seed production, 1994, 1996 and 2000, this study compared moleculsrly four maize endogamic lines generated by the INIFAP Maize Program: L1, L2, L3 and L4. DNA was extracted from seed embryos and subjected to PAPD protocols, after which phylogenetic relations were established between treatments using the program LCDMV (molecular distance between varieties calculation software), using the parameters: Seuil distance $=0,95 \%$ confidence, the estimator of distances of Nei and $\mathrm{Li}$, and the method of average clustering (UPGMA). In the comparison by age, the dendro-graph obtained grouped equal genotypes according to their respective age, with outstanding similitude coefficient reached by the unon of ages L2 (90\%) and L4 (80\%), while the similarity value for L1 was $70 \%$. The genotipic capacity of the lines to preserve their genome was higher in L2, followed by L4 and L1. The results indicated the effectiveness of the RAPD protocol to discriminate within and between genetically-related genotypes according to age, and to distinguish within and between maize lines irrespective of their age.
\end{abstract}

Key words: Zea mays, genetic identity, fingerprinting, RAPDs, natural ageing.

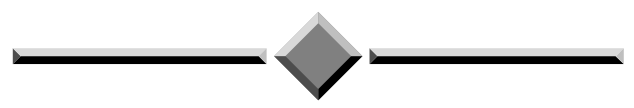

1 Recibido: 20 de febrero, 2008. Aceptado: 19 de marzo, 2009. Proyecto de Investigación interinstitucional (IPN-UNAM-INIFAP).

2 Departamentos de Bioprocesos y Bioingeniería, respectivamente, Unidad Profesional Interdisciplinaria de Biotecnología (UPIBI), Instituto Politécnico Nacional (IPN). Av. Acueducto s/n. 07340, La Laguna Ticoman. México, D. F. Tel. (01-55) 5729-6000, ext. 56343. ggutierrez@ acei.upibi.ipn.mx (Autor para correspondencia)y gramirez55120@hotmail.com.

3 Facultad de Química, Universidad Nacional Autónoma de México (UNAM). Av. Universidad y Copilco, Ciudad Universitaria, México, D. F. elpidio@servidor.unam.mx

4 Programas de Maíz y Semillas, Campo Experimental Valle de México (CEVAMEX), Instituto Nacional de Investigaciones Forestales, Agrícolas y Pecuarias (INIFAP). Apartado Postal 10.56230, Chapingo, México. arevajolu@yahoo.com.mx; jvirgen_vargas@hotmail.com, respectivamente. 


\section{INTRODUCCIÓN}

La renovación y multiplicación de las líneas básicas de los programas de mejoramiento genético de especies de cultivo y de producción de semillas, tanto oficiales como privados, es impostergable cuando se agota la existencia de semilla en almacén, o bien, cuando su viabilidad llega a niveles mínimos. En consecuencia, es habitual tener diferentes edades u orígenes (lugar y año de producción de semillas) para un mismo genotipo, situación que con frecuencia conduce a comparar las edades para constatar la preservación de la pureza e identidad genética de los materiales genéticos involucrados.

Para su comparación, se siembran los genotipos de diferente edad junto con la semilla del mejorador y para la cual se tiene la descripción tradicional, es decir, basada en caracteres morfológicos y agronómicos (Zúñiga 2007).

Es diversa la utilidad de la descripción detallada de los materiales genéticos bajo mejoramiento o ya liberados, sirve para identificarlos y registrarlos para su comercialización, como criterio para eliminar plantas fuera de tipo durante la multiplicación de semilla certificada, etc.

Los procedimientos convencionales para verificar la identidad genética de las especies de cultivo, han sido soporte primordial del sistema de certificación de semillas implantado a nivel mundial; no obstante, la identificación fehaciente se complica conforme es mayor la cercanía genética de los genotipos, situación cada vez más frecuente en los programas genotécnicos dado que se liberan materiales que difieren en pocos genes o hasta en uno solo.

Por tanto, es relevante incorporar procedimientos que proporcionen mayor sensibilidad a la descripción de los genotipos bajo mejoramiento (Copeland y McDonald 2001), y cuanto más exhaustiva y fidedigna sea ésta mejor. En este sentido, el empleo de metodologías moleculares, como las huellas genómicas, incrementa la precisión de la caracterización varietal, dado que proveen información directamente a nivel del ADN, por lo que no son afectadas por el ambiente y enriquecen la información disponible para distinguir, con alto grado de certeza, individuos entre y dentro de genotipos sin importar su cercanía genética (Zúñiga 2007).

Los marcadores moleculares del ADN, son secuencias genómicas localizadas en un mismo locus y difieren en su secuencia de bases nitrogenadas a consecuencia de mutaciones o rearreglos cromosómicos, de manera que reflejan directamente las variaciones a nivel del ADN, son dominantes o codominantes, y son estables e independientes del ambiente de desarrollo del organismo analizado. Estas características los hacen útiles en la identificación varietal (Valadez y Kahl 1999).

Mediante la huella genómica, se pueden identificar plantas individuales dentro de una población o en una serie de líneas endogámicas y distinguir entre plantas cuya composición genética difiera ligeramente (McDonald 1999).

A la fecha se han implementado varios protocolos de huellas genómicas o marcadores moleculares, siendo la amplificación del ADN polimórfico al azar (RAPD) una metodología eficiente para establecer el grado de similitud entre individuos de una población a nivel genómico (Fragoso et al. 2006). Además, la técnica de la RAPD posee varias de las características deseables para los marcadores moleculares señaladas por Valadez y Kahl (1999), como su facilidad de operación, y reducida cantidad de ADN y de una calidad moderada, bajo costo, etc.

La confiabilidad y consistencia de los datos obtenidos con la aplicación de la RAPD, están en función directa de aspectos como utilizar un solo lote, proveedor y marca de reactivos, preparar soluciones madre de los reactivos, utilizar el mismo material y equipo, e inclusive que sea la misma persona quien procese todas las muestras (Durán 2008).

Para la producción y certificación de semillas resulta crucial conocer los factores de la certeza y reproducibilidad de las metodologías moleculares empleadas para dictaminar la identidad genética de las mismas, precisamente para su aplicación e interpretación correctas. En este sentido, se deben considerar los cambios genómicos que ocurren en las semillas durante su almacenamiento (Gutiérrez et al. 1993, Desai et al. 1997), mismos que pudieran hacer variar la huella molecular entre las semillas recién cosechadas y las envejecidas del mismo genotipo.

La pureza genética es un factor prioritario de la calidad seminal y su nivel debe conservarse durante sus sucesivas fases de multiplicación (original, básica, registrada y certificada), de manera que la composición genética del material genético sea la misma desde su obtención y hasta llegar al agricultor (Copeland y 
McDonald 2001); sin embargo, suelen ocurrir variaciones motivadas por mutaciones, cruzamiento natural, enfermedades, la técnica de polinización, mezclas mecánicas, o bien, por procesos de senescencia durante el almacenamiento (Desai et al. 1997).

Se han realizado estudios sobre el efecto de la edad de las semillas sobre su vigor (Hernández et al. 2000), o bien, analizando los cambios fisiológicos ocurridos en ellas después de su almacenamiento prolongado (Fragoso et al. 2006); y se han obtenido diferencias significativas entre semillas viejas y nuevas en viabilidad, protrusión radicular, acumulación de materia seca, etc. También se ha documentado un efecto genotípico para la susceptibilidad al envejecimiento, ya sea natural o artificialmente inducido (Gutiérrez et al. 1993).

Se considera entonces que las alteraciones cromosómicas acumuladas en las semillas repercuten en la transcripción y, por ende, en la traducción del genoma, ocasionando trastornos bioquímicos y fisiológicos. Además, es probable que se modifique sustancialmente la huella genómica de las semillas de las líneas endogámicas envejecidas con respecto a la obtenida para semillas nuevas (Welsh y McClelland 1990, Williams et al. 1990).

Este trabajo pretende contribuir al conocimiento del potencial de los marcadores moleculares para la caracterización e identificación fidedigna de genotipos de maíz, abordando los trastornos genómicos suscitados durante el almacenamiento de las semillas y que eventualmente modifican los sitios de reconocimiento para los iniciadores de la RAPD entre semillas de diferente edad.

El objetivo del presente trabajo fue comparar dos edades de semillas de cuatro líneas endogámicas de maíz, mediante la amplificación aleatoria del ADN polimórfico (RAPD), así como establecer la confiabilidad de esta técnica de marcadores moleculares para identificar genotipos pese a su envejecimiento.

\section{MATERIALES Y MÉTODOS}

Se utilizaron embriones extraídos manualmente de semillas de cuatro líneas endogámicas de maíz (L1-L4), desarrolladas en el Programa de Maíz del Instituto Nacional de Investigaciones Forestales y Agropecuarias (INIFAP), cada una de ellas (excepto L3) con diferente año de producción 1994 ó 1996 y 2000 (Cuadro 1) y con un vigor contrastante, evaluado
Cuadro 1. Tratamientos y año de producción de las líneas endogámicas de maíz bajo estudio. Campo Experimental Valle de México (CEVAMEX) - Instituto Nacional de Investigaciones Forestales, Agrícolas y Pecuarias (INIFAP), Chapingo, México, 2007.

\begin{tabular}{llcc}
\hline & Tratamiento & Línea & Edad (años) \\
\hline 1 & L1 SV $^{\dagger}$ & L1 & 1994 \\
2 & L1 SN & & 2000 \\
3 & L2 SV & & 1996 \\
4 & L2 SN & L2 & 2000 \\
5 & L3 SN & & 2000 \\
6 & L4 SV & L3 & 1996 \\
7 & L4SN & & 2000 \\
8 & Levadura & (Saccharomyces & cerevisiae) \\
\hline
\end{tabular}

$\dagger=$ Semillas viejas

$\dagger=$ Semillas nuevas

计 $=$ Control negativo

éste por la capacidad de preservar la aptitud germinativa de las semillas durante su estancia en el almacén. $\mathrm{El}$ almacenamiento de los materiales de referencia fue en una bodega sin control de temperatura ni humedad, en el Campo Agrícola Experimental Valle de México (Chapingo, México).

El estudio aquí descrito se efectuó durante el 2007 en el Laboratorio de Biotecnología Molecular de la Unidad Profesional Interdisciplinaria de Biotecnología del Instituto Politécnico Nacional (UPIBI-IPN), y en la Facultad de Química de la Universidad Nacional Autónoma de México (UNAM).

\section{Extracción de ADN genómico}

La purificación del ADN de cada genotipo, se realizó siguiendo el protocolo de Dellaporta et al. (1983), a partir de $0,1 \mathrm{~g}$ de embriones completos de semillas secas de maíz como ya se indicó antes, los cuales se lavaron dos veces con agua bidestilada, se secaron superficialmente con toallas de papel, e inmediatamente después se congelaron con nitrógeno líquido y se homogenizaron en un mortero estéril preenfriado hasta obtener un molido fino, el cual se transfirió a un tubo Falcon con $4 \mathrm{ml}$ de solución amortiguadora de extracción CTAB (100 mM Tris-HCl, pH 7,5; $700 \mathrm{mM}$ $\mathrm{NaCl} ; 50$ mM EDTA, pH 8,0; 1\% p/v CTAB), a la cual se le agregaron $25 \mu \mathrm{l}$ de $\beta$-mercaptoetanol (Sigma) y 
previamente se calentó a $60{ }^{\circ} \mathrm{C}$. Se mezcló suave y frecuentemente el contenido del tubo Falcon durante los 45 min de incubación. Una vez fría la mezcla, se le agregaron $4 \mathrm{ml}$ de la solución cloroformo/alcohol isoamílico $(24: 1 \mathrm{v} / \mathrm{v})$ y se mezcló por 10 minutos. Se centrifugó a $12.000 \mathrm{rpm}$ por $20 \mathrm{~min}$ a temperatura ambiente $\left(25^{\circ} \mathrm{C}\right)$. Se recuperó el sobrenadante con una micropipeta con puntas cortadas y se colocó en un nuevo tubo estéril. Después de centrifugar, se agregaron $2,5 \mathrm{ml}$ de isopropanol frío y se mezcló agitando levemente. El ADN se dejó precipitar entre 15 y 30 min a $-20{ }^{\circ} \mathrm{C}$; conseguido lo anterior, se centrifugó nuevamente a $12.000 \mathrm{rpm}$ a temperatura ambiente por 7 min. Se desechó el sobrenadante, se lavó la pastilla con $5 \mathrm{ml}$ de la solución de lavado (76\% p/v Etanol, 0,2 M NaOAc,) y se centrifugó a $12.000 \mathrm{rpm}$ por 7 min. Se descartó el sobrenadante y la pastilla se dejó secar a temperatura ambiente por una hora colocando el tubo invertido sobre papel absorbente. Finalmente, se disolvió la pastilla en $2 \mathrm{ml}$ del amortiguador TE (10 mM Tris-HCl, pH 8,0; 1 mM EDTA pH 8,0) a $4{ }^{\circ} \mathrm{C}$, durante $12 \mathrm{~h}$.

\section{Cuantificación y verificación de la calidad del ADN}

Para cuantificar el ADN se agregaron $15 \mu \mathrm{lde}$ cada muestra de ADN extraído a $735 \mu \mathrm{l}$ de TE $(10$ mM Tris-HCl, pH 8,0; 1 mM EDTA pH 8,0) y se leyó la densidad óptica a $260 \mathrm{~nm}$ (DO 260) en un espectrofotómetro (Beckman DU-350; California, USA). La concentración de cada muestra se calculó con la relación (CIMMYT 2006):

$$
\begin{aligned}
& {[\mathrm{ADN}] \mu \mathrm{g} / \mu \mathrm{l}=(\mathrm{DO} 260 \mathrm{~nm})(\mathrm{FD})(50 \mu \mathrm{g} / \mu \mathrm{l})} \\
& 1000^{-1}
\end{aligned}
$$

Donde:

$$
\begin{aligned}
& {[\mathrm{ADN}] \mu \mathrm{g} / \mu \mathrm{l}=\text { Concentración de ADN }} \\
& (\mathrm{DO} 260 \mathrm{~nm})=\text { Lectura a } 260 \mathrm{~nm} \\
& \text { FD }=\text { Factor de dilución }=(50)
\end{aligned}
$$

La calidad del ADN se constató mediante electroforesis en gel de agarosa (Top Vision E GQ), al $0,7 \% \mathrm{p} / \mathrm{v}$, disuelta en amortiguador TAE $1 \mathrm{X}(40 \mathrm{mM}$ Tris- $\mathrm{HCl} \mathrm{pH} 8,0,20 \mathrm{mM}$ de acetato de sodio, $2 \mathrm{mM}$ EDTA). Se empleó una cámara de electroforesis horizontal (Termo EC Classic CSSU911) de 9 x $11 \mathrm{~cm}$, se cargaron $100 \mathrm{ng}$ de las muestras con $2 \mu \mathrm{l}$ de azul de bromofenol, el gel se corrió durante 90 min a un voltaje de $50 \mathrm{~mA}$. Por último, el gel se tiñó con bromuro de etidio $(1 \mu \mathrm{g} / \mathrm{ml})$. Posteriormente se uniformizó la concentración del ADN a $10 \mathrm{ng} / \mu \mathrm{l}$, cantidad utilizada para la amplificación, para ello las muestras de trabajo se diluyeron con TE $(10 \mathrm{mM}$ Tris- $\mathrm{HCl}, \mathrm{pH} 8,0 ; 1 \mathrm{mM}$ EDTA pH 8,0), adicionando el volumen pertinente a cada una de ellas, y se almacenaron a $4{ }^{\circ} \mathrm{C}$.

\section{Iniciadores}

La amplificación al azar del ADN genómico de los genotipos se hizo mediante la reacción en cadena de la Taq ADN-polimerasa (PCR). Se utilizaron 13 iniciadores (oligonucleótidos) pertenecientes a las series g y c de Carl Roth (USA): g01, g03, g06, g14, g16, g20, g18, g15, c07, c11, c12, c13 y c15 (Cuadro 2).

Cuadro 2. Secuencias de los oligonucleótidos utilizados para la amplificación aleatoria del ADN polimórfico. Facultad de Química, Universidad Nacional Autónoma de México (UNAM), México. 2007.

\begin{tabular}{cc}
\hline Iniciador & $\begin{array}{c}\text { Secuencia nucleotídica } \\
\mathbf{5} \text {, a 3, }\end{array}$ \\
\hline $\mathrm{g} 01$ & CTACGGAGGA \\
$\mathrm{g} 03$ & GAGCCCTCCA \\
$\mathrm{g} 06$ & GTGCCTAACC \\
$\mathrm{g} 14$ & GGATGAGACC \\
$\mathrm{g} 15$ & ACTGGGACTC \\
$\mathrm{g} 16$ & AGCGTCCTCC \\
$\mathrm{g} 18$ & GGCTCATGTG \\
$\mathrm{g} 20$ & TCTCCCTCAG \\
$\mathrm{c} 07$ & GTCCCGACGA \\
$\mathrm{c} 11$ & AAAGCTGCGG \\
$\mathrm{c} 12$ & TGTCATCCCC \\
$\mathrm{c} 13$ & AAGCCTCGTC \\
$\mathrm{c} 15$ & GACGGATCAG \\
\hline
\end{tabular}

\section{Amplificación aleatoria del ADN polimórfico (RAPD)}

La reacción para la amplificación se efectuó en un volumen final de $25 \mu \mathrm{l}$, agregando los reactantes 
(Fermentas Co.) en el mismo orden con el que se indican en el Cuadro 3.

Cuadro 3. Mezcla de reacción utilizada para la amplificación aleatoria del ADN polimórfico (RAPD). Facultad de Química, Universidad Nacional Autónoma de México (UNAM), México. 2007.

\begin{tabular}{lcc}
\hline Reactante & [Final] & $\begin{array}{c}\text { Volumen } \\
(\boldsymbol{\mu l})\end{array}$ \\
\hline ddH20 & --------- & 15,5 \\
Amortiguador PCR $(10 \mathrm{X} \mathrm{KCl})$ & $1 \mathrm{x}$ & 2,5 \\
MgCL2 $(25 \mathrm{mM})$ & $1.5 \mathrm{mM}$ & 1,5 \\
dNTPs $(10 \mathrm{mM})$ & $200 \mu \mathrm{M}$ & 0,5 \\
Taq $(5 \mathrm{U} / \mu \mathrm{l})$ & $2 \mathrm{U} /$ reacción & 0,4 \\
ADN $(50 \mathrm{ng} / \mu \mathrm{l})$ & $80 \mathrm{ng} /$ reacción & 1,6 \\
Iniciador $(50 \mathrm{ng} / 1)$ & $30 \mathrm{pm} /$ reacción & 3 \\
\hline
\end{tabular}

La mezcla de reacción se cubrió con $25 \mu \mathrm{l}$ de aceite mineral grado biología molecular (Sigma). La reacción de amplificación se llevó a cabo en el termociclador Mastercycler (Eppendorf Scientific, USA), con el programa que a continuación se detalla: a) Desnaturalización de 1 min a $94{ }^{\circ} \mathrm{C}$, b) 55 ciclos de: $30 \mathrm{seg}$ a $94{ }^{\circ} \mathrm{C}$; $30 \mathrm{seg}$ a $35^{\circ} \mathrm{C}, \mathrm{y} 1,5 \mathrm{~min}$ a $72{ }^{\circ} \mathrm{C}$, y c) $2,5 \min$ a $72{ }^{\circ} \mathrm{C}$, este último de extensión final.

Los fragmentos amplificados se resolvieron por electroforesis en geles de agarosa $(1,2 \%, \mathrm{p} / \mathrm{v})$ y se tiñeron con bromuro de etidio (CIMMYT 2006) para posteriormente fotografiarlos.

\section{Fotodocumentación}

Los geles se fotografiaron en el transiluminador Gel Logic 440 (Imaging System, Kodak, USA) y el análisis de los pesos moleculares de las bandas obtenidas se realizó con el programa Kodak Molecular Imaging versión 4.0.

\section{Análisis de datos genómicos}

Los perfiles genómicos, es decir, los fragmentos amplificados obtenidos para cada iniciador, se codificaron empleando el número 1 para indicar la presencia de la banda y 0 para denotar su ausencia. Con la codificación de las bandas se elaboró la matriz base de datos (MBD). La MBD constó de 45 columnas y ocho filas, en correspondencia con las bandas obtenidas y los genotipos estudiados, esto es, los siete tratamientos bajo estudio más el ADN de levadura (Saccharomyces cerevisiae), utilizado como control negativo.

Para construir los dendogramas se utilizó el programa LCDMV (Calculation Software of Molecular Distances Between Varieties) (CIMMYT, 2003), con los parámetros: Distancia de Seuil $=0$, Confiabilidad del $95 \%$, el estimador de distancias de Nei y Li, y el método de agrupamiento del promedio (UPGMA) (Dubreuil et al. 2003).

\section{RESULTADOS Y DISCUSIÓN}

Después de la extracción del ADN de los embriones de las semillas de las líneas endogámicas de maíz, se eligió al azar uno de ellos (L4SN) para utilizarlo como templado en la PCR, con los 13 iniciadores disponibles para el experimento. Con este escrutinio de prueba se identificaron y seleccionaron los oligonucleótidos que amplificaron mayor número de fragmentos, de buena resolución y polimórficos, mismos que fueron g $06, \mathrm{~g} 15$, g 18, c 07 y c 13 (Cuadro 2), y con los cuales se desarrollaron los perfiles de bandeo en los ocho tratamientos.

\section{Huellas genómicas}

Mediante la amplificación al azar del ADN polimórfico (RAPD) se generó la huella genómica para cada combinación genotipo-iniciador, observándose que los fragmentos amplificaron nítida y claramente, excepto para L1SN (carril 5), tratamiento para el cual si se lograron bandas definidas con el resto de los cebadores (patrones de bandeo no incluidos), mostrándose a continuación los perfiles de bandeo para los oligonucleótidos g 15, c 07 y g 18 (Figuras 1 y 2).

Cabe mencionar la presencia de amplificación en el blanco experimental (todos los ingredientes excepto ADN) con el iniciador g 18 (372,3 y 1.078,6 pb, Cuadro 2), la cual se considera producto de alguna contaminación ocurrida a pesar del rigor con que se hicieron los experimentos, de cualquier manera esas bandas se eliminaron de la codificación, al igual que todas aquellas equivalentes en posición, nitidez e intensidad, generadas en los genomas de maíz, y así garantizar la confiabilidad del perfil de bandeo (Williams et al. 1990). 


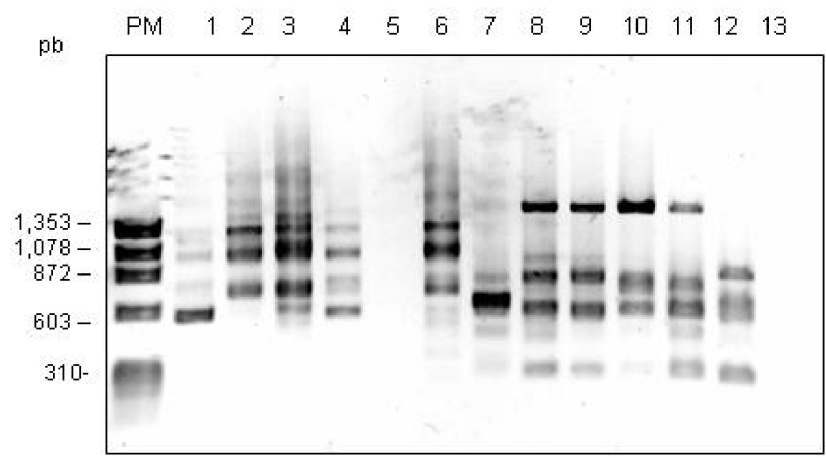

A

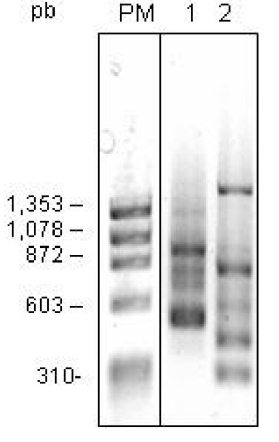

B

Figura 1. A) Huellas genómicas obtenidas con el iniciador g 15 (carriles 1 a 6) y con c 07 (carriles 7 a 12), en ambos casos, el orden de los tratamientos fue: L4SV, L2SV, L2SN, L1SV, L1SN, L3SN. Carril 13, blanco experimental. B) Huella genómica de la línea L4SN con los iniciadores g 15 y c 07, (carriles 1 y 2, respectivamente). Facultad de Química, Universidad Nacional Autónoma de México (UNAM), México. 2007.

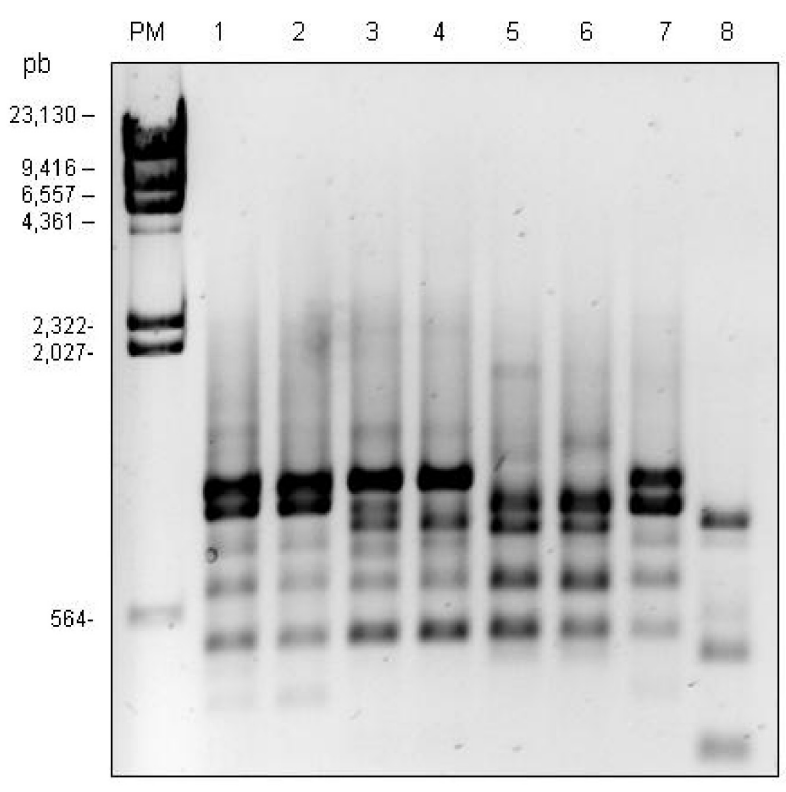

Figura 2. Huellas genómicas obtenidas con el iniciador g 18 (carriles uno a siete), el orden de las líneas endogámicas fue: L4SN, L4SV, L2SV, L2SN, L1SV, L1SN y L3SN. En el carril 8, se ubica el blanco experimental. Facultad de Química, Universidad Nacional Autónoma de México (UNAM), México. 2007.
Como control negativo en la construcción de los dendogramas de similitud, se obtuvo la huella genómica de la levadura (Saccharomyces cerevisiae), utilizando los mismos oligonucleótidos que para los genotipos bajo análisis.

Una vez digitalizadas las imágenes de los geles, se determinaron los pesos moleculares de los fragmentos amplificados, advirtiéndose que las bandas consideradas iguales (por su posición, nitidez e intensidad) diferían en menos de 100 pares de bases (pb), por lo que aquellas que tuvieron entre si un mayor número de pb se consideraron diferentes para efectos de la codificación binaria.

Para cada oligonucleótido se obtuvieron de ocho a 10 bandas para todos los tratamientos, incluyendo a la levadura, con una longitud de 82,28 a 1.753 pb y se produjeron en total 45 bandas, de las cuales sólo cinco fueron monomórficas en los genomas de maíz, lo que indicó una alta sensibilidad de la técnica para detectar polimorfismos y así diferenciar entre los genotipos utilizados (Zúñiga 2007).

\section{Dendogramas}

En el dendograma generado para la codificación de los fragmentos de ADN amplificados al azar (Figura 3), los nodos para L2, L4 y L1 tuvieron porcentajes 


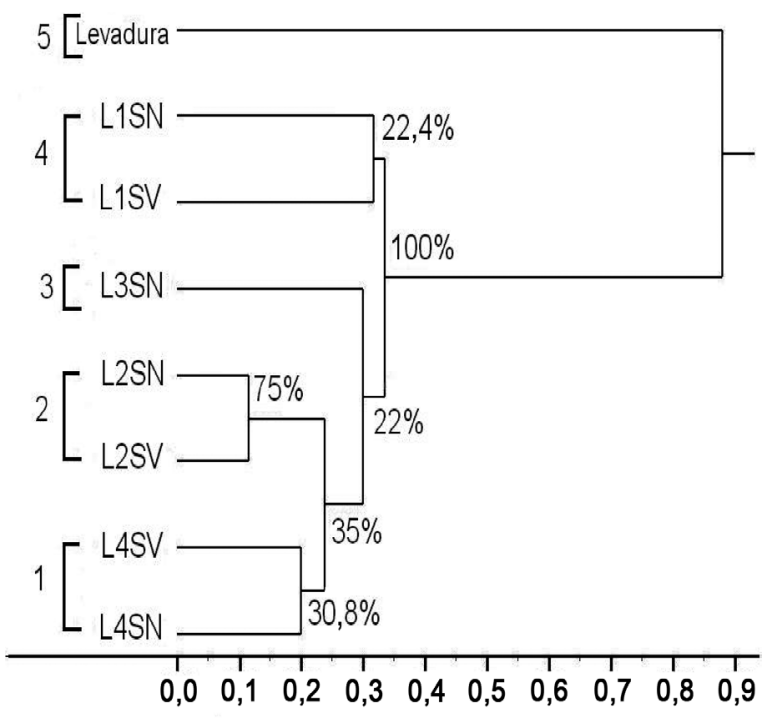

Figura 3. Dendograma (LCDMV, CIMMYT 2003), generado por la matriz base de datos (ocho tratamientos). La escala indica diferencias entre las líneas endogámicas y los porcentajes en los nodos expresan la consistencia de los grupos utilizando 500 repeticiones (bootstrapping). Unidad Profesional Interdisciplinaria de Biotecnología (UPIBI) - Instituto Politécnico Nacional (IPN). México. 2007.

de persistencia del $75 ; 30,8$ y $22,4 \%$, respectivamente. El coeficiente de correlación cofenética fue del 0,99, el cual se considera un ajuste óptimo (Sokal 1979), es decir, las agrupaciones resultantes para genotipos y edades corresponden a las características intrínsecas de los tratamientos, lo cual denota la confiabilidad del método seguido para la comparación molecular de las edades de las líneas de maíz en el presente estudio.

En el dendograma obtenido con la MBD (Figura 3) se aprecia la formación de cinco grupos, (uno para cada línea y el de la levadura). Además, cada línea se unió con sus dos edades, expresando esto la capacidad de la RAPD para diferenciar entre genotipos y para encontrar las similitudes dentro de los mismos. L3SN, línea endogámica para la cual sólo se dispuso del origen reciente, sirvió para corroborar precisamente que la RAPD distingue de manera consistente genotipos distintos.

Cabe mencionar que en el dendograma se expresan las diferencias entre clases o grupos con un intervalo de cero a uno, por lo que para la interpretación de los resultados se calculó el complemento (la similitud) y se expresó en porcentaje, es decir, se analizó la homología molecular detectada entre y dentro de genotipos.

Es factible que la conformación de los grupos (Figura 3) haya estado relacionada con los daños acumulados en el ADN seminal durante el almacenamiento, y también con la tolerancia al envejecimiento que cada material genético pudiera expresar (Gutiérrez et al. 1993, Cruz et al. 2003, Fragoso et al. 2006). De este modo, correspondió a L2 la mayor similitud entre edades (90\%), seguida por L4 (80\%), y después por L1 (70 \%, aproximadamente), por lo que se pudiera establecer en el mismo orden anterior, el ya citado nivel de tolerancia genotípica al deterioro del ADN. Estudios relacionados también reportan homologías del $90 \%$ entre genotipos distintos y con mayor cantidad de iniciadores (Ozino et al. 1998).

Además de la conservación genotípicamente diferencial del ADN durante el añejamiento, en los datos moleculares (Figura 3) se observa la unión de las distintas edades del mismo genotipo (L1, L2 y L4), lo cual indica que se mantuvo la identidad genética de los materiales en sus incrementos de semilla, al menos dentro de los límites de la sensibilidad de la RAPD, y esta preservación es precisamente la finalidad del incremento de semilla.

De lo antes expuesto y en concordancia con trabajos similares (Zúñiga 2007, Durán 2008), se evidenció la robustez del método seguido para discriminar genotipos con distinta edad, en oposición a reportes que aducen que la RAPD no es una técnica apropiada para este propósito (Welsh y McClelland 1990, Williams et al. 1990, Jianhua et al. 1996, Filho y McDonald 1998).

La fase siguiente de nuestro estudio será correlacionar la comparación molecular de las edades contrastantes de las cuatro líneas, con su desempeño fisiológico y, en consecuencia, con su longevidad.

\section{CONCLUSIONES}

Mediante la RAPD, se distinguieron estadísticamente las cuatro líneas endogámicas de maíz analizadas, y cada cual se agrupó con base en su edad. El RAPD identificó inter e intra genotípicamente los materiales, independientemente de la edad de sus semillas.

La agrupación por similitud entre las edades de L2 fue del $90 \%$, para L4 del $80 \%$, y para L1 del 70 $\%$, valores indicativos de la aptitud de cada línea para 
mantener su integridad genómica durante el almacenamiento (L2>L4>L1).

La caracterización molecular constituye un valioso componente de la descripción varietal de maíz, particularmente en su proceso de certificación de semillas.

\section{AGRADECIMIENTOS}

A la Secretaría de Investigación y Posgrado del IPN (SIP: 20071401) por financiar el proyecto, a la Facultad de Química de la UNAM por la utilización de su infraestructura, al INIFAP por la donación de las semillas empleadas, y a la Comisión de Operación y Fomento de Actividades Académicas del IPN (COFAA), por la beca otorgada al primer autor.

\section{LITERATURA CITADA}

CIMMYT (Centro Internacional de Mejoramiento de Maíz y Trigo). 2006. Protocolos de laboratorio: Laboratorio de Genética Molecular Aplicada del CIMMYT. $3^{\mathrm{a}} \mathrm{ed}$. El Batán, Texcoco, México. 100 p.

Copeland, LO; McDonald, MB. 2001. Principles of seed science and technology. Kluwer Academic Publishers. 4 ed. p. 297-343.

Cruz-Pérez, AB, González, VA; Mendoza, MC; Ortega, YML. 2003. Marcadores fisiológicos de la tolerancia al envejecimiento de semilla de maíz. Agrociencia 37(4): 371-381

Dellaporta, SL; Word, J; Hicks, JB. 1983. A plant DNA minipreparation: Version II. Plant. Mol. Biol. Rep. 1: 19-21.

Desai, BB; Kotecha, PM; Salunkhe, DK. 1997. Seeds handbook: biology, production, processing and storage. Marcel Dekker, Inc. USA. 627 p.

Dubreuil, P; Dillman, C; Warburton, M; Crossa, J; Franco, BC. 2003. Users manual for the LCDMV software (calculation software of molecular distance between varieties) for fingerprinting and genetic diversity studies. CIMMYT. El Batán Texcoco, Méx. 21 p.

Durán, D. 2008. Caracterización fisiológica y molecular de semillas de maíz azul. Tesis de Maestría en Ciencias.
Unidad Profesional Interdisciplinaria de Biotecnología - Instituto Politécnico Nacional (UPIBI-IPN). México, DF. $98 \mathrm{p}$

Fragoso, EM; Gutiérrez, GF; Virgen, J. 2006. Repercusiones físicas y fisiológicas del envejecimiento natural de semillas de cruzas simples de maíz y sus líneas progenitoras. Revista Fitotecnia Mexicana 29 (Número especial 2): 75-80.

Gutiérrez, G; Cruz, F; Moreno, J; González, VA; Vázquez, JM. 1993. Natural and artificial seed ageing in maize: germination and DNA synthesis. Seed Science Research 3: 279-285.

Gutiérrez, GF; Virgen, J; Arellano, JL. 2007. Germinación y crecimiento inicial de semillas de maíz con envejecimiento natural. Agronomía Mesoamericana 18 (2): 163-170.

Hernández, AJ; Carballo, A; Hernández, A; González, FV. 2000. Ponderación de variables de calidad fisiológica para la medición del vigor en semilla de maíz. Revista Fitotecnia Mexicana 23: 239-250.

Jianhua, Z; Mcdonald, MB; Sweeney, PM. 1996. Random amplified polymorphic DNA (RAPDs) from seeds of differing soybean and maize genotypes. Seed Science and Technology 24: 513-522.

Marcos-Filho, J; McDonald, MB. 1998. Sensitivity of RAPD analysis, germination and vigour test to detect the intensity of deterioration of naturally and artificially aged soybean seeds. Seed Science and Technology 26: 141-157.

McDonald, MB. 1999. Seed deterioration: physiology, repair and assessment. Seed Science and Technology 27: $177-237$

Ozino, OI; Piatti, P; Cravanzola, F. 1998. RAPD-PCR for the molecular characterization of Beauveria brongniartii isolates useful as biocontrol agents of the European cockchafer Melolontha melolontha. In: Bridge, P; Couteaudier, Y; Clarkson, J. eds. Molecular variability of fungal pathogens. 239-251. CAB Int.

Sokal, RR. 1979. Testing statistical significance of geographic variation patterns. Systematic Zool. 28: 227-231.

AGRONOMÍA MESOAMERICANA 20(1): 01-09.2009 
Valadez, E; Kahl, G. 1999. Categorías básicas para el análisis de marcadores genético-moleculares. Depto. de Fitotecnia, Universidad Autónoma Chapingo, Texcoco, México. 182 p.

Welsh, J; Mclelland, M. 1990. Fingerprinting genomes using PCR with arbitrary primers. Nucleic Acid Research. 18 (24): 7213-7218.
Williams, JGK; Kubelik, AR; Livak, KJ; Rafalski, JA; Tingey, SV. 1990. ADN polymorphisms amplified by arbitrary primers are useful as genetic markers. Nucleic Acid Research 18 (22): 6531-6535.

Zuñiga-Navarrete, F. 2007. Comparación molecular de edades de semillas de maíz. Tesis de licenciatura. Unidad Profesional Interdisciplinaria de Biotecnología - Instituto Politécnico Nacional (UPIBI-IPN). México, DF. 51 p. 
